\section{REPAIR OF CHORDAE TENDINEAE FOR RHEUMATIC MITRAL VALVE DISEASE}

\section{A twenty-year experience}

Sixty-two patients with rheumatic mitral valve disease (mean age $42.2 \pm$ 10.2 years) underwent repair of chordae tendineae between June 1974 and May 1994. Chordal shortening was done in 38 patients, fenestration in 17, resection of secondary chordae in 3 , replacement in 2 , and transposition in 2. In 41 patients, mitral commissurotomy was also done. Ring annuloplasty was done in all patients. The mean follow-up was 10.2 years (range 2 months to 20 years). The completeness of follow-up during the closing interval (January to July 1994) was $100 \%$. Hospital mortality occurred in four patients $(6.5 \%)$ and nine patients died during the late follow-up. The actuarial survival curve at 20 years was $65.8 \% \pm 10 \%$. Six patients with mitral valve dysfunction (restenosis 4 , insufficiency 2 ) and one with aortic valve dysfunction (structural deterioration of bioprosthesis) underwent reoperation. The actuarial curve of freedom from reoperation at 20 years for mitral valve dysfunction was $73.1 \% \pm 10.5 \%$. In the 49 surviving patients, a Doppler echographic study during the closing interval showed a mean mitral valve area of $1.9 \pm 0.3 \mathrm{~cm}^{2}$. In the 43 patients with a repaired native valye, absent or trivial mitral regurgitation was documented in $\mathbf{3 5}$ and mild or moderate regurgitation in 8 . In conclusion, repair of chordae tendineae in rheumatic mitral valve disease when feasible is a stable and safe procedure with a low prevalence of reoperation. However, the type of reconstructive operation and experience of the surgical team are major considerations in successful repair of the mitral valve. (J THORAC CARDIOVASC SURG 1996;111:211-7)

José M. Bernal, MD, José M. Rabasa, MD, Juan J. Olalla, MD, Manuel F. Carrión, MD, Alicia Alonso, MD, and José M. Revuelta, MD, Santander, Spain

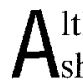
lhough mitral valve reconstruction has been shown to provide better results than valve replacement, ${ }^{1-3}$ there is a paucity of proper comparisons as to the long-term stability of the results obtained with different reparative operations. Technical difficulties in the repair of the subvalvular apparatus and the limited experience with this type of complex operation have been major impediments to the widespread repair, rather than replacement, of the incompetent mitral valve. On the other hand,

From the Department of Cardiovascular Surgery, Hospital Universitario Valdecilla, Universidad de Cantabria, Santander, Spain.

Received for publication Nov. 28, 1994.

Accepted for publication Feb. 9, 1995.

Address for reprints: José M. Bernal, MD, Department of Cardiovascular Surgery, Hospital Universitario Valdecilla, 39008 Santander, Spain.

Copyright (C) 1996 by Mosby-Year Book, Inc.

$0022-5223 / 96 \$ 5.00+0 \quad \mathbf{1 2} / \mathbf{1} / \mathbf{6 4 1 6 3}$ most of the reports tend to describe the results of repair in a mixed population with different causes of the valve disease. ${ }^{4,5}$ This report retrospectively analyzes the results obtained in a 20 -year period in patients with rheumatic valvular disease who underwent repair of chordae tendineae.

\section{Patients and methods}

Between June 1974 and May 1994, 354 patients with rheumatic mitral valve disease, excluding those with pure mitral stenosis treated by isolated open mitral commissurotomy, papillary muscle split, or both, underwent an operation for mitral valve reconstruction with a ring annuloplasty at our institution. Repair of chordae tendineae in association with mitral valve annuloplasty was done in $62(17.5 \%)$ of 354 patients. The patient selection criteria were based exclusively on intraoperative findings and feasibility of repairing the subvalvular apparatus. Data in these 62 patients constitute the basis for this report.

There were 14 men and 48 women with a mean age of $42.2 \pm 10.2$ years (range 18 to 73 years). At the time of operation, $19(30.6 \%)$ patients were in New York Heart 
Table I. Mitral valve lesions in 62 patients undergoing repair of chordae tendineae

\begin{tabular}{lcc}
\multicolumn{1}{c}{ Anatomic lesion } & $\begin{array}{c}\text { No. of } \\
\text { patients }\end{array}$ & Percent \\
\hline Annular dilatation & 26 & 41.9 \\
Commissural fusion & 30 & 48.4 \\
Leaflet calcification & 4 & 6.5 \\
Leaflet retraction & 4 & 6.5 \\
Chordal elongation & 38 & 61.3 \\
Subvalvular apparatus fusion & 19 & 30.6 \\
Chordal rupture & 5 & 8.1 \\
\hline
\end{tabular}

Association functional class II, $34(54.8 \%)$ in class III, and $9(14.5 \%)$ in class IV. Before operation, $14(22.6 \%)$ patients were in sinus rhythm and $48(77.4 \%)$ in atrial fibrillation. Forty-two (67.7\%) patients had an isolated mitral valve lesion, $17(27.4 \%)$ an associated tricuspid valve lesion, $1(1.6 \%)$ an associated aortic valve lesion, and $2(3.2 \%)$ triple valve disease.

The mitral valve disease consisted of combined stenosis and insufficiency in $25(40.3 \%)$ patients and mixed lesions with predominant insufficiency in $37(59.7 \%)$. Preoperative evaluation included cardiac catheterization in 30 (48.4\%) patients, echocardiography in $15(24.2 \%)$, or both in $17(27.4 \%)$. In 47 patients mean systolic pulmonary artery pressure was $41.4 \pm 12.1 \mathrm{~mm} \mathrm{Hg}$ and mean mitral transvalvular gradient was $8.4 \pm 5.3 \mathrm{~mm} \mathrm{Hg}$.

Intraoperative testing of mitral valve competence and surgical procedures used for valve repair have already been described, ${ }^{6-9}$ and recently the use of transesophageal Doppler echocardiographic study has been reported. Mitral valve findings are described in Table I. The mitral anulus was found to be dilated in $41.9 \%$ of patients, the mitral leaffets were affected in $61.3 \%$ of patients, and the commissures were fused in $48.4 \%$ of patients. Rheumatic lesions of chordae tendineae were found in all patients. These involved marginal chordae in $59(95.2 \%)$ patients and medial (secondary) chordae in the remaining 3 $(4.8 \%)$. Chordal elongation was present in $61.3 \%$ of cases, severe fusion in $30.6 \%$, and rupture in $8.1 \%$.

The type of technique used for mitral valve repair is shown in Table II. The Duran flexible ring was used in $95.2 \%$ of patients and the rigid Carpentier ring in $4.8 \%$. A total of $66.1 \%$ of patients underwent open commissurotomy and $4.8 \%$ underwent partial leaflet resection. Chordal shortening was done in $61.3 \%$ of patients, fenestration in $27.4 \%$, secondary chordal resection in $4.8 \%$, replacement ${ }^{10}$ in $3.2 \%$, and transposition in $3.2 \%$. A total of 170 mitral valve reparative procedures were done in 62 patients, for an average of 2.7 procedures per patient. Operations on other valves included tricuspid valve repair in 19 patients (Duran flexible ring annuloplasty in 19, concomitant tricuspid commissurotomy in 7) and aortic valve operation in 2 (bioprosthesis 1, valve repair 1). Myocardial revascularization was done in three patients, atrial septal defect closure in two, left atrial thrombectomy in six, left atrial appendage exclusion in eight, and other cardiac procedures in four.

Surviving patients in sinus rhythm were given antiplatelet therapy for 3 months after the operation $(n=12)$. Those patients with atrial fibrillation received crystalline
Table II. Surgical techniques in 62 patients with rheumatic mitral valve disease undergoing repair of chordae tendineae

\begin{tabular}{lcc}
\hline \multicolumn{1}{c}{ Operation } & $\begin{array}{c}\text { No. of } \\
\text { patients }\end{array}$ & Percent \\
\hline Annular repair* & 62 & 100 \\
Commissurotomy & 41 & 66.1 \\
Leaflet resection & 5 & 8.1 \\
Chordal shortening & 38 & 61.3 \\
Chordal fenestration & 17 & 27.4 \\
Chordal resection & 3 & 4.8 \\
Chordal replacement & 2 & 3.2 \\
Chordal transposition & 2 & 3.2 \\
\hline
\end{tabular}

*Flexible ring annuloplasty, 59 patients; rigid ring annuloplasty, 3 patients.

warfarin sodium (Coumadin) for 3 months after operation $(n=35)$ or on a long-term basis when the patient was considered to be at especially high risk for late thromboembolic complications because of a giant left atrium or massive thrombus $(n=11)$. However, this thromboembolic prophylaxis was modified according to the patient's requirements during follow-up.

Follow-up of all surviving patients was done at regular intervals of 3,6 , and 12 months after operation and then annually. Follow-up was completed from January to July 1994. The completeness of follow-up during the closing interval was $100 \%$. All patients were seen at our outpatient clinic and had a Doppler echographic study during the closing interval. The mean follow-up was 10.2 years, with a range from 2 months to 20 years.

The values are expressed as means of the average and standard deviation. The $\mathrm{X}^{2}$ test was used to analyze the significance between variables. Actuarial curves were obtained by the life-table method.

\section{Results}

Hospital mortality occurred in four $(6.4 \%)$ patients. The causes of death were heart failure in two patients and massive hemorrhage in two. Hospital mortality for patients undergoing isolated mitral valve operation was $4.8 \%(2 / 42)$ and for patients having polyvalvular operations $10 \%(2 / 20)(p=$ not significant).

Of the 58 surviving patients, nine died during the late follow-up $(15.5 \%)$. The causes of death were heart failure in three patients, thromboembolism in one, noncardiac death in one, and unknown in four. The actuarial survival curve at 20 years was $65.8 \% \pm$ $10 \%$ (Fig. 1). For the group of 42 patients who underwent isolated mitral valve repair, the actuarial survival curve at 20 years was $75.3 \% \pm 13.3 \%$, whereas for the 20 patients who had polyvalvular operation it was $52.1 \% \pm 18.6 \%(p=$ not significant) (Fig. 2).

Nine patients had a thromboembolic episode 


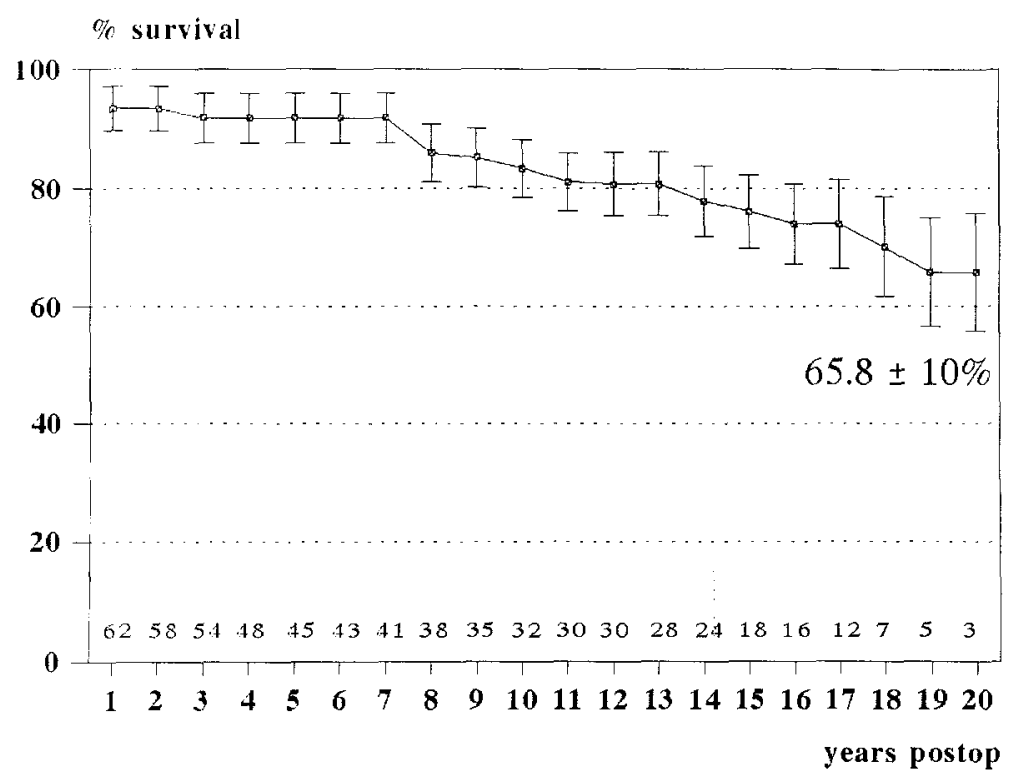

Fig. 1. Actuarial probability of survival after mitral valve repair. Number above x-axis represents total number of patients at risk.

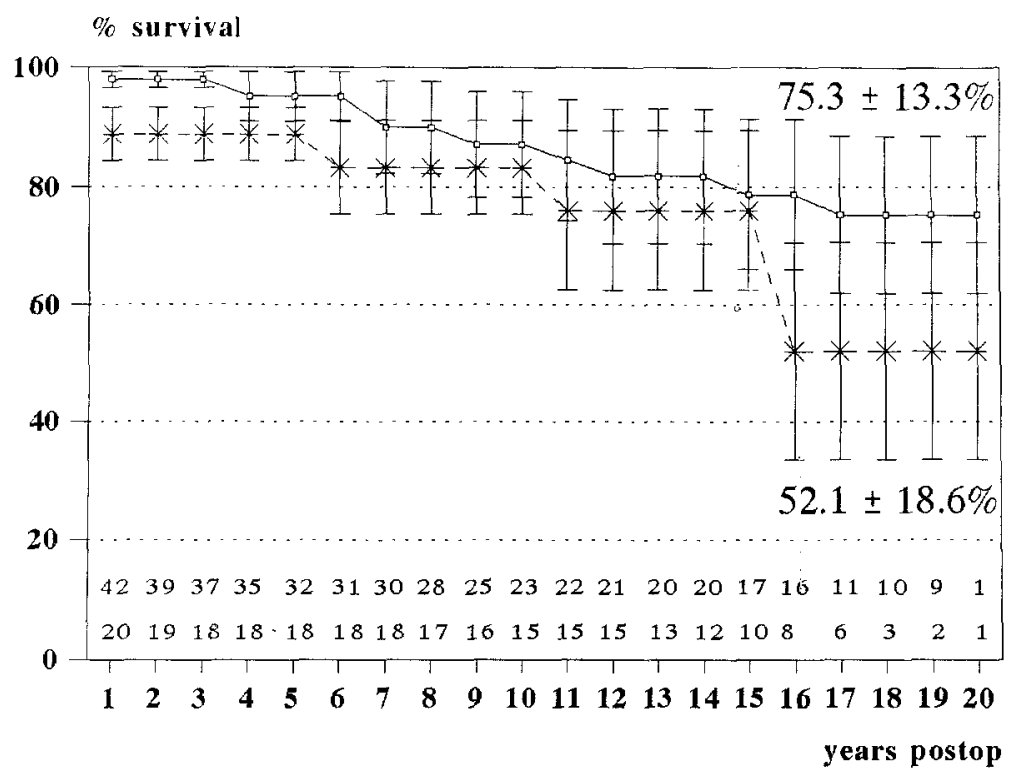

Fig. 2. Actuarial probability of survival in patients with isolated mitral valve lesions (squares) and in patients with multiple valve lesions (asterisks). Number above $\mathrm{x}$-axis represents total number of patients at risk.

during the follow-up: two peripheral and seven central (4 transient, 2 with permanent neurologic impairment, and 1 death). The actuarial survival curve for freedom from thromboembolic events at 20 years was $74.3 \% \pm 7.7 \%$ (Fig. 3 ). There were no statistically significant differences in survival free from thromboembolic events between patients with isolated mitral valve repair and patients with polyvalvular disease or between patients with or without anticoagulation or those in atrial fibrillation or sinus rhythm.

Seven patients required a valve reoperation. The 


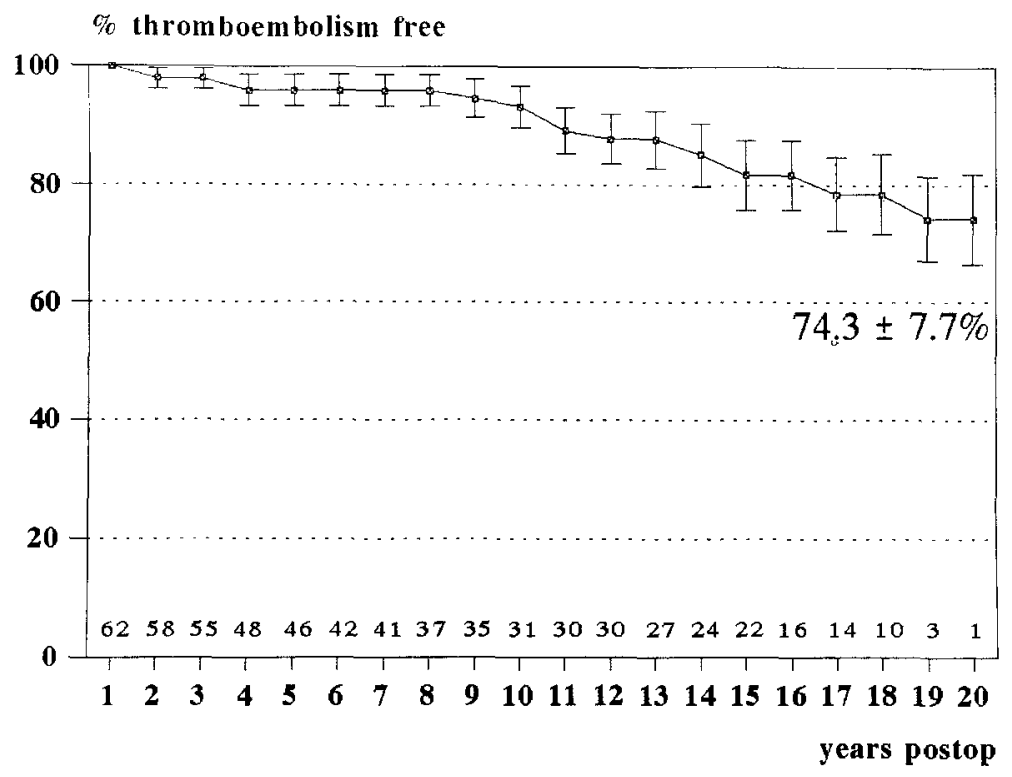

Fig. 3. Survival free from thromboembolic events. Number above $x$-axis represents total number of patients at risk.

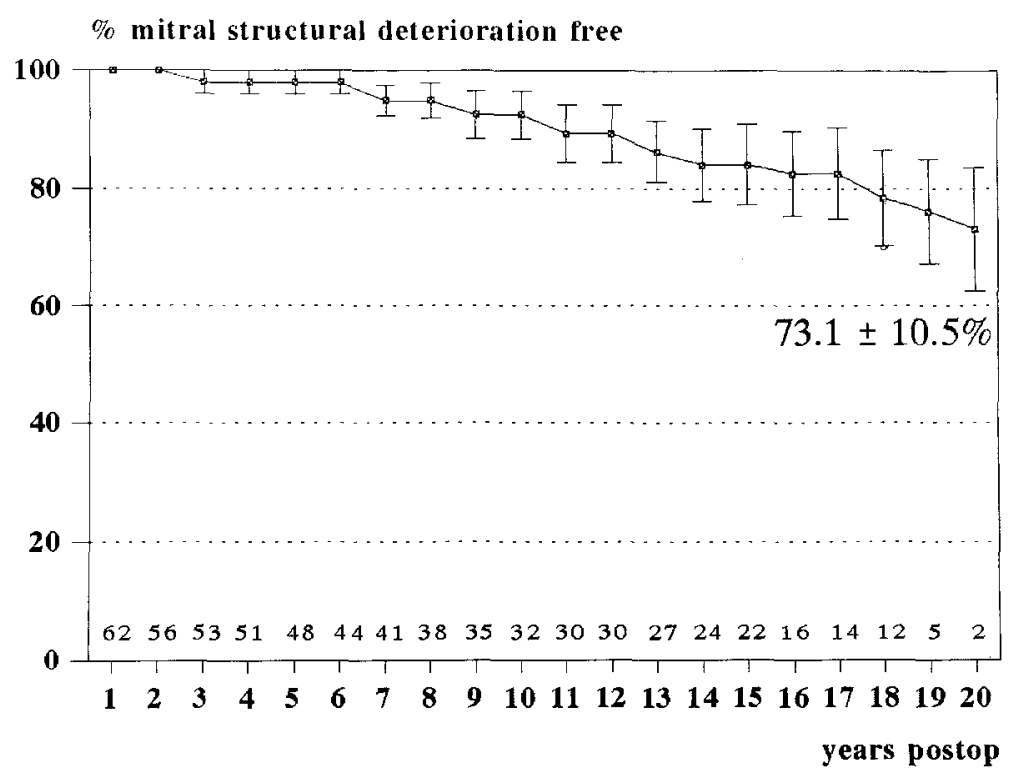

Fig. 4. Survival free from reoperation. Number above $x$-axis represents total number of patients at risk.

reoperation was necessary because of mitral valve dysfunction in six patients (stenosis in 4 after an interval of $194 \pm 33.2$ months, mitral insufficiency in 2 after an interval of $51 \pm 33.7$ months) and because of structural deterioration of the aortic bioprosthesis in one. There was no mortality at reoperation. The actuarial curve of freedom from reoperation at 20 years for mitral valve dysfunction was $73.1 \% \pm$
$10.5 \%$ (Fig. 4). Other valve-related complications such as infective endocarditis or ring dehiscence did not occur. The actuarial curve of freedom from valve-related complications at 20 years was $47.1 \% \pm$ $9.4 \%$ (Fig. 5). Linear rates of valve-related complications were $4.2 \% \pm 1.2 \%$ per patient-year. Statistically significant differences in survival free from reoperation and survival free from valve-related 


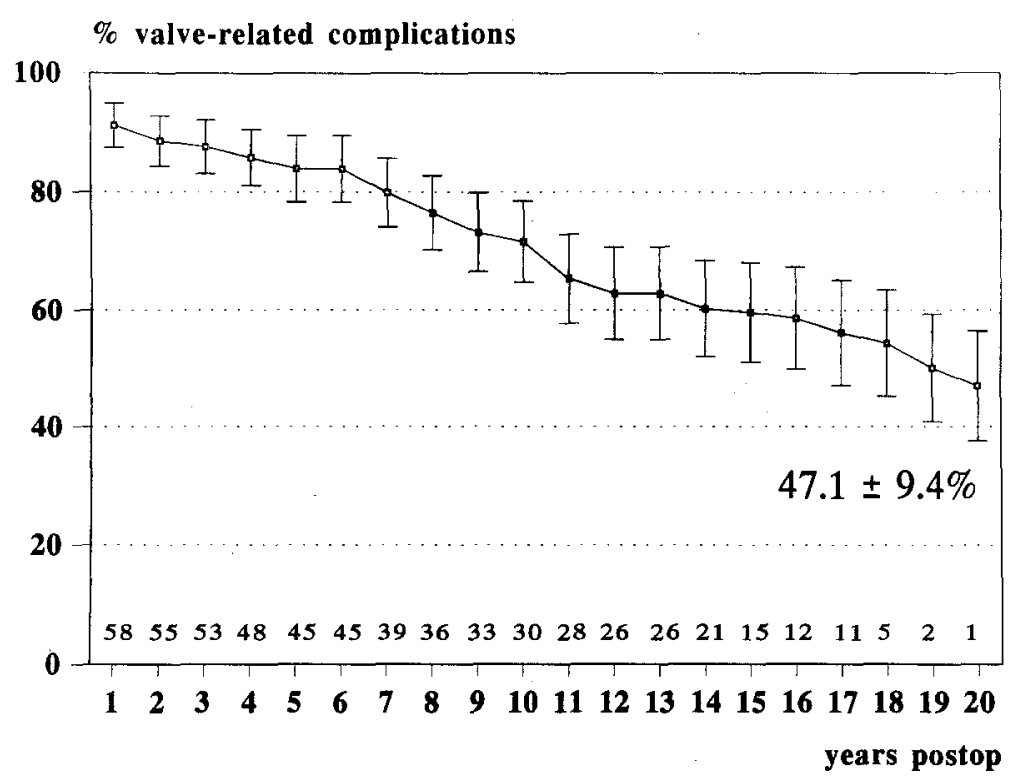

Fig. 5. Survival free from valve-related complications. Number above $\mathrm{x}$-axis represents total number of patients at risk.

complications between patients with isolated mitral operation and those with polyvalvular disease were not found.

Forty-three $(87.8 \%)$ of the 49 surviving patients at the closing interval of follow-up had the repaired native mitral valve and were in functional class I or II. In these 43 patients, mean left ventricular systolic diameter was $29.5 \pm 6.8 \mathrm{~mm}$ and mean diastolic diameter $48.4 \pm 6.2 \mathrm{~mm}$. Mean left ventricular ejection fraction was $61.7 \% \pm 9.8 \%$ and mean left atrial diameter was $43.7 \pm 10.5 \mathrm{~mm}$. The mean mitral valve area was $1.9 \pm 0.3 \mathrm{~cm}^{2}$. Absent or trivial mitral regurgitation was documented in 35 (81.4\%) patients and mild or moderate regurgitation in 8 $(18.6 \%)$.

\section{Discussion}

Although data from different reports have confirmed the predictability and stability of the results achieved with reconstructive procedures of the mitral valve, 111,12 repair of chordae tendineae is done occasionally and only by some surgical teams. In most patients, valve replacement continues to be a widely accepted approach for rheumatic disease because of inadequacy of the valve anatomy to be repaired. Repair of chordae tendineae is conditioned by the limited surgical experience, the variety of operations used, and the lack of terminology to classify both subvalvular abnormalities and types of valvular procedures, as well as by the absence of long-term results with this kind of complex operation.

On the other hand, conservative surgery of the mitral valve often implies repair of the leaflets, the anulus, and each structure of the subvalvular apparatus. In our study, an average of 2.7 procedures per patient was required to complete valve reconstruction successfully. The presence of abnormalities of the chordae is frequently a major impediment to the repair of incompetent mitral valves by means of mitral valve annuloplasty alone.

Although different attempts to repair chordae tendineae have been made in the United States as early as $1960,{ }^{13,14}$ chordal repair was eventually abandoned as a result of its unpredictable efficacy. The principles of mitral valve repair introduced by Carpentier and coworkers ${ }^{15,16}$ renewed interest in mitral valve reconstruction and encouraged various European and North American groups to use conservative operations regularly. ${ }^{1,17-21}$ Newer techniques were evolved and others were used with indications different from those originally intended.

Mitral valve repair in rheumatic mitral valve disease is technically more difficult and less stable than repair in ischemic and degenerative lesions because of the progressive nature of the pathologic condition and the type of patient population affected. ${ }^{4,22,23}$ This confirms the importance of re- 
porting the results in patients with a homogeneous cause of the disease. ${ }^{24-26}$

Although our study, like others, ${ }^{24,25}$ has shown the necessity to repair the subvalvular apparatus in most patients with rheumatic heart disease, the degree and extent of chordal involvement are primary determinants of the likelihood of successful repair. Leaflet retraction is a most common finding in rheumatic mitral valve disease that frequently represents a major impediment for mitral valve repair. In our experience, only four patients with mild leaflet retraction were successfully treated by means of ring annuloplasty to increase leaflet coaptation. Chordal elongation, a less common finding in these patients, is more suitable for repair. Intraoperative two-dimensional and Doppler echocardiography done before cardiac operations provides a reliable assessment of the feasibility of valve repair versus replacement. ${ }^{27}$ However, partial homograft replacement of the mitral valve is an alternative for patients with extensive rupture or elongation of marginal chordae, commissural involvement, and anterior leaflet disease that cannot be repaired by standard techniques. ${ }^{28,29}$

Advanced morphologic changes in the subvalvular apparatus, progression of native valve disease, and lack of experience have been considered important risk factors for failed mitral valve repair., 23, 30 One of the arguments against this kind of operation is that chordal repair is time consuming and results in a much longer ischemic time and significantly higher hospital mortality than straight replacement. In the present study, however, the hospital mortality rate was lower than that for mitral valve replacement. ${ }^{31}$ Long-term survival at 20 years has been lower in patients with polyvalvular disease than in patients with isolated mitral valve lesions $(52.1 \% \pm$ $18.6 \%$ versus $75.3 \% \pm 13.3 \%$ ).

Thromboembolism has been the most common late postoperative complication in this group of patients. However, given that a substantial number of patients had polyvalvular disease with a high rate of preoperative risk factors, such as atrial fibrillation, giant left atrium, previous thromboembolism, and left atrial thrombosis, the prevalence of postoperative thromboembolic events has not been higher than that reported for bioprosthetic valve replacement. ${ }^{31}$

Only seven patients in this series underwent reoperation because of mitral valve dysfunction. When valve insufficiency was the cause of failure, reoperation was done early in comparison with the timing of reoperation for restenosis $(51 \pm 33.7$ months versus $194 \pm 33.2$ months). These findings may indicate that in most cases residual insufficiency is a result of incorrect indication for repair, technical errors, or incomplete repair causing early valvular incompetence. Restenosis of the repaired mitral valve is usually a result of progression of rheumatic disease. A Doppler echographic study done during the closing interval showed, in $81.4 \%$ of patients, a normal functioning mitral valve, a mean valvular area of $1.9 \pm 0.3 \mathrm{~cm}^{2}$, and no evidence of valve incompetence.

In conclusion, repair of chordae tendineae in unselected patients with theumatic mitral valve disease when feasible has been shown to be a stable and safe procedure with acceptable long-term results, in particular with regard to a low prevalence of reoperation. There are, however, insufficient data about the long-term results of this procedure in young populations with rheumatic disease. The type of reconstructive operation and experience of the surgical team are major considerations in the successful repair of the mitral valve.

We are indebted to Carlos G. Durán, MD, for his valuable active surgical participation in the early series of patients. We thank Mrs. Charo Sánchez for secretarial help and Marta Pulido, MD, for editing the manuscript and editorial assistance.

\section{REFERENCES}

1. Cohn LH, Kowalker W, Bhatia S, et al. Comparative morbidity of mitral valve repair versus replacement for mitral regurgitation with and without coronary artery disease. Ann Thorac Surg 1988;45:284-90.

2. Krayenbuehl HP. Surgery for mitral regurgitation: repair versus valve replacement. Eur Heart J 1986;7: 638-43.

3. Sand ME, Naftel DC, Blackstone EH, Kirklin JW, Karp RB. A comparison of repair and replacement for mitral valve incompetence. J THORAC CARDIOvASC SuRG 1987;94:208-19.

4. Deloche A, Jebara VA, Relland JYM, et al. Valve repair with Carpentier techniques. J ThoraC CARdiovASC SURG 1990;99:990-1002.

5. Fernandez J, Joyce DH, Hirschfeld KJ, et al. Valverelated events and valve-related mortality in 340 mitral valve repairs: a late phase follow-up study. Eur J Cardiothorac Surg 1993;7:263- 70.

6. Duran CMG, Ubago JL. Clinical and hemodynamic performance of a totally prosthetic ring for atrioventricular valve reconstruction. Ann Thorac Surg 1976; 22:458-63.

7. Duran CMG. Reconstructive procedures of the mitral 
valve including ring annuloplasty. In: Cohn LH, ed. Modern techniques in surgery: cardiac/thoracic. 1st ed. Mount Kisko, New York: Futura, 1979:1-6.

8. Duran CG. Repair of anterior mitral left chordal rupture or elongation (the flip over technique). J Card Surg 1986;1:161-5.

9. Pomar JL, Cucchiara G, Gallo I, Duran CMG. Intraoperative assessment of mitral valve function. Ann Thorac Surg 1978;25:354- 5.

10. Revuelta JM, Garcia R, Gaite L, Val F, Garijo F. Generation of chordae tendineae with polytetrafluoroethylene stents: results of mitral valve chordae replacement in sheep. J Thorac Cardiovasc Surg 1989;97:98-103.

11. Galloway A, Colvin SB, Baumann FG, et al. A comparison of mitral valve reconstruction with mitral valve replacement: intermediate-term results. Ann Thorac Surg 1989;47:655-62.

12. Craver JM, Cohen C, Weintraub WS. Case-matched comparison of mitral valve replacement and repair. Ann Thorac Surg 1990;49:964- 9.

13. Wooler GH, Nixon PGF, Grimshow VA, Watson DA. Experiences with the repair of mitral valve in mitral incompetence. Thorax 1962;17:49-57.

14. McGoon DC. Repair of mitral insufficiency due to ruptured chordae tendineae. J THORAC CARDIOvasc SurG 1960;39:357-62.

15. Carpentier A. La valvuloplastie reconstitutive: une nouvelle technique de valvuloplastie mitrale. Presse Med 1969;77:251-3.

16. Carpentier A, Deloche A, Dauptain J, et al. A new reconstructive operation for correction of mitral and tricuspid insufficiency. J THORAC Cardiovasc Surg 1971;61:1-13.

17. Duran CG, Pomar JL, Revuelta JM, et al. Conservative operation for mitral insufficiency: critical analysis supported by postoperative hemodynamic studies of 72 patients. J THORAC CARDIOVASC SURG 1980;79:326-37.

18. Kay JH, Zubiate P, Mendez MA, Vanstrom N, Yokohama T. Mitral valve repair for regurgitant mitral insufficiency. Am Heart J 1978;96:253-62.

19. Gregory F Jr, Takeda R, Silva S, Façanha L, Meier MA. A new technique for repair of mitral insufficiency caused by ruptured chordae of the anterior leaflet. $\mathbf{J}$ Thorac Cardiovasc SuRG 1988;96:765-8.
20. Frater RWM, Gabbay S, Shore D, Factor S, Strom J. Reproducible replacement of elongated or ruptured mitral valve chordae. Ann Thorac Surg 1983; 35:14-28.

21. Cosgrove DM, Chavez AM, Lytle BW, et al. Results of mitral valve reconstruction. Circulation 1986; 74(Suppl):I82-7.

22. Antunes MJ. Mitral valve repair in the 1990 s. Eur J Cardiothorac Surg 1992;6(suppl):13-6.

23. Michel PL, Lung B, Blanchard B, Luxereau P, Dorent R, Acar J. Long-term results of mitral valve repair for non-ischaemic mitral regurgitation. Eur Heart J 1991; 12(Suppl):39-43.

24. Antunes MJ, Magalhaes MP, Colsen PR, Kinsley RH. Valvuloplasty for rheumatic mitral valve disease: a surgical challenge. J THORAC CARDIOvasc SuRg 1987; 94:44-56.

25. Duran CMG, Gometza B, De Vol EB. Valve repair in rheumatic mitral disease. Circulation 1991;84(Suppl): III125-32.

26. Bernal JM, Rabasa JM, Vilchez FG, Cagigas JC, Revuelta JM. Mitral valve repair in rheumatic disease: the flexible solution. Circulation 1993;88:174653.

27. Stewart WJ, Currie PJ, Salcedo EE, et al. Evaluation of mitral leaflet motion by echocardiography and jet direction by Doppler color flow mapping to determine the mechanism of mitral regurgitation. J Am Coll Cardiol 1992;20:1353-61.

28. Revuelta JM, Cagigas JC, Bernal JM, Val F, Rabasa JM, Lequerica MA. Partial replacement of mitral valve by homograft: an experimental study. J THORAC Cardiovasc Surg 1992;104:1274-9.

29. Revuelta JM, Bernal JM, Rabasa JM. Partial homograft replacement of mitral valve. Lancet 1994;344: 514.

30. Fernandez J, Joyce DH, Hirschfeld K, et al. Factors affecting mitral valve reoperation in 317 survivors after mitral valve reconstruction. Ann Thorac Surg 1992;54:440-8.

31. Bernal JM, Rabasa JM, Cagigas JC, Echevarria J, Carrion MF, Revuelta JM. Valye-related complications with the Hancock I porcine bioprosthesis. J Thorac Cardiovasc Surg 1991;101:871-80. 